\title{
Characterization of a proximal Sp1 response element in the mouse Dlk2 gene promoter
}

\author{
Samuel Rivero ${ }^{1,2}$, Almudena Ruiz-García', María JM Díaz-Guerra', Jorge Laborda ${ }^{1}$ and José J García-Ramírez ${ }^{*}$
}

\begin{abstract}
Background: DLK2 is an EGF-like membrane protein, closely related to DLK1, which is involved in adipogenesis. Both proteins interact with the NOTCH1 receptor and are able to modulate its activation. The expression of the gene DIk2 is coordinated with that of DIk1 in several tissues and cell lines. Unlike DIk1, the mouse DIk2 gene and its locus at chromosome 17 are not fully characterized.

Results: The goal of this work was the characterization of D/k2 mRNA, as well as the analysis of the mechanisms that control its basal transcription. First, we analyzed the D/k2 transcripts expressed by several mouse cells lines and tissues, and mapped the transcription start site by 5' Rapid Amplification of CDNA Ends. In silico analysis revealed that Dlk2 possesses a TATA-less promoter containing minimal promoter elements associated with a CpG island, and sequences for Inr and DPE elements. Besides, it possesses six GC-boxes, considered as consensus sites for the transcription factor Sp1. Indeed, we report that Sp1 directly binds to the D/k2 promoter, activates its transcription, and regulates its level of expression.

Conclusions: Our results provide the first characterization of D/k2 transcripts, map the location of the Dlk2 core promoter, and show the role of Sp1 as a key regulator of D/k2 transcription, providing new insights into the molecular mechanisms that contribute to the expression of the D/k2 gene.
\end{abstract}

\section{Background}

Dlk2 encodes for a transmembrane glycoprotein with six epidermal growth factor-like (EGF-like) motifs in the extracellular domain, a single transmembrane domain and a short intracellular tail. These features place DLK2 as a member of the EGF-like family of proteins, in which NOTCH receptors and their ligands are included [1]. The proteins of this family mediate protein-protein interactions through their EGF-like repeats, modulating cell fate differentiation in numerous cell types. DLK2 shares most of its structural features with DLK1, with the highest homology located at the EGF-like domains. DLK1 participates in several differentiation processes, including adipogenesis [1-6], differentiation of hepatocytes $[7,8]$, hematopoiesis [2,9-14], osteogenesis [15-17], adrenal gland and neuroendocrine cell differentiation [18-23], peripheral and central nervous system differentiation $[22,24]$, growth arrest, and increased malignancy

\footnotetext{
* Correspondence: JoseJavier.GRamirez@uclm.es

'Facultad de Medicina/Centro Regional de Investigaciones Biomédicas (CRIB), Universidad de Castilla-La Mancha. Calle Almansa 14. 02006 Albacete. Spain Full list of author information is available at the end of the article
}

of undifferentiated tumors [21,25-27]. DLK1 has also been reported to participate in the wound healing process [28]. DLK2 has been shown to participate also in adipogenesis [1], but its role in other differentiation processes is yet unknown.

$D l k 2$ expression can be detected in several adult mouse tissues, showing a more widespread pattern of expression than $D l k 1$. Dlk2 is highly expressed in lung, brain, adipose tissue, testicles, adult liver, placenta, ovaries and thymus [1]. Little is known about the regulation of $D l k 2$ expression, although it seems clear that the expression of $D l k 1$ and $D l k 2$ appears to be coordinated in some instances in vitro. Thus, their expression levels in response to cell confluence vary in opposite directions. Interestingly, when the expression level of one homolog is modified in one direction, the enforced change exerts an opposite effect on the expression level of the other, both in 3T3-L1 and C3H10T1/2 cells [1]. That seemingly coordinated expression appears to occur also during tissue development: along mouse embryogenesis and postnatal growth, $D l k 1$ is highly expressed during the development of fetal liver, when no
C Biomed Central 
expression of $D l k 2$ is detected; $D l k 2$ expression in liver can only be detected 16 days after birth [1]. All these data suggest the likely existence of coordinated control mechanisms for $D l k 1$ and $D l k 2$ gene expression.

Previous to this work, in the UCSC genome browser (http://genome.ucsc.edu), three full-length transcripts, BC118057, BC122518, and BC019431, had been assigned to Dlk2. The main differences among those Dlk2 transcripts are restricted to the 5' end of the mRNA, with most of the transcripts being identical in the majority of mRNA's 3' regions. To the best of our knowledge, experimental support regarding any of the three abovementioned transcripts is lacking, excluding a few publications regarding the role of $D l k 2$ [1,29]. In this paper, we describe the first experimental characterization of $D l k 2$ transcription, showing that only one out of the three predicted transcripts, BC019431, could be detected in all the mouse cell lines and tissues analyzed. We have also mapped the transcription initiation site, which correlates with the abovementioned transcript, although with 14 additional bp at the 5' end. The Dlk2 core promoter is located within a CpG island extending beyond the transcription start site (TSS). Bioinformatics analysis showed the presence of two core promoter elements, the Initiator Element (Inr), and the Downstream Promoter Element (DPE), which have been described as necessary for basal transcription in other genes. Finally, as it is characteristic of TATA-less promoters with an Inr element, we have shown that Sp1, a member of the Sp/ KLF family of zinc finger transcription factors that recognize GC/GT boxes present in many GC-rich promoters, is able to bind to the $D l k 2$ promoter and control Dlk2 basal transcription.

\section{Results}

\section{Characterization of Dlk2 mRNA}

Mouse Dlk2 is a gene located at chromosome 17 (position 46434370-46440220), containing six exons. Previous to this work, three mRNAs have been associated to Dlk2 in GenBank: [GenBank: BC118057, BC122518, and BC019431] (http://genome.ucsc.edu) (Figure 1A). $\mathrm{BC} 118057$ and BC122518 show almost the same exonintron distribution, just differing in the second exon of $\mathrm{BC} 122518$, which is not present in BC118057. BC019431 share the last four exons with the former two mRNAs. However, the transcription start site and the splicing sites for the first and second exons are different between the two sets of mRNAs clones, BC118057/ BC122518 and BC019431. Surprisingly, BC019431 has been considered as a chimeric cDNA for the last few years, although it has been the cDNA routinely used by our research group, and the only one appearing in the few publications regarding $D l k 2[1,29]$. Thus, our first objective was to confirm or refute if BC019431 was indeed a real cDNA, and to analyze which of the three mRNAs assigned to Dlk2 are expressed in different mouse tissues and cell lines. Considering the differences among the mRNAs, and to facilitate the nomenclature of the transcripts, we classified them in two groups, according to the position of their TSS: a first group, including $\mathrm{BC} 118057$ and $\mathrm{BC} 122518$, was named as variant 1, (V1, Figure 1A); a second group, including only BC019431, was named variant 2 (V2, Figure 1A). We next designed specific oligonucleotides capable to discriminating between V1 and V2 (Figure 1A), and studied by RT-PCR whether any, or both $D l k 2$ mRNA variants described above were present in total RNAs from different origins. We prepare cDNA from total RNA extracted from heart, spleen, testis, brain, and lung of adult 129/C57 mice. The rest of the cDNAs were prepared separately from different mouse cell lines in which $D l k 2$ is expressed, including 3T3-L1, NIH3T3, C3H10T1/2 and AT3F cells [1] (see Materials and Methods). Lastly, mouse genomic DNA was used as a control for primer amplification. As shown in Figure 1B, both PCR primer sets were able to amplify the expected DNA fragments from the genomic DNA sample. However, when cDNA was used as a template, either from tissues or from each cell line, only the $\mathrm{V} 2_{\mathrm{U}} / \mathrm{V}_{\mathrm{L}}$ oligonucleotide pair could amplify a fragment of the expected size from all the samples (Figure $1 \mathrm{~B}$ ). The $\mathrm{V} 1_{\mathrm{U}} / \mathrm{V}_{\mathrm{L}}$ oligonucleotide pair could not amplify a DNA fragment of the expected size in any of the nine samples analyzed. However, when brain cDNA was used as a template, and the PCR conditions were pushed to try to amplify any trace cDNA, a faint $700 \mathrm{bp}$ fragment could be detected (Figure 1B). Our data thus indicated that only the V2 transcript can be detected in all the samples analyzed, suggesting that clone BC019431 derives from a real mRNA and it is not an artifact. It can also be concluded that V1 transcripts, as they have been described in the genomic databases, are not present in the tissues and cell lines tested in this work or, if they are, their abundance is much lower than that of the V2 transcript. It is interesting to note the possible existence of a different, yet uncharacterized, splice variant that can only be detected in brain, which we plan to analyze in detail in future studies.

To further characterize the Dlk2 mRNA, we next focused on mapping the TSS. We first analyzed the expression level of $D l k 2$ in several cell lines, and decided to use the mouse hepatoma cell line AT3F as a source of RNA, due to its high level of $D l k 2$ expression (Figure 1C). We used the Rapid Amplification of cDNA Ends assay (SMART RACE cDNA amplification kit, Clontech, EEUU) to map the 5' region of Dlk2 mRNA. Using a $D l k 2$ specific oligonucleotide, we amplified a unique 880 bp DNA band (Figure 1D). This PCR product was next 


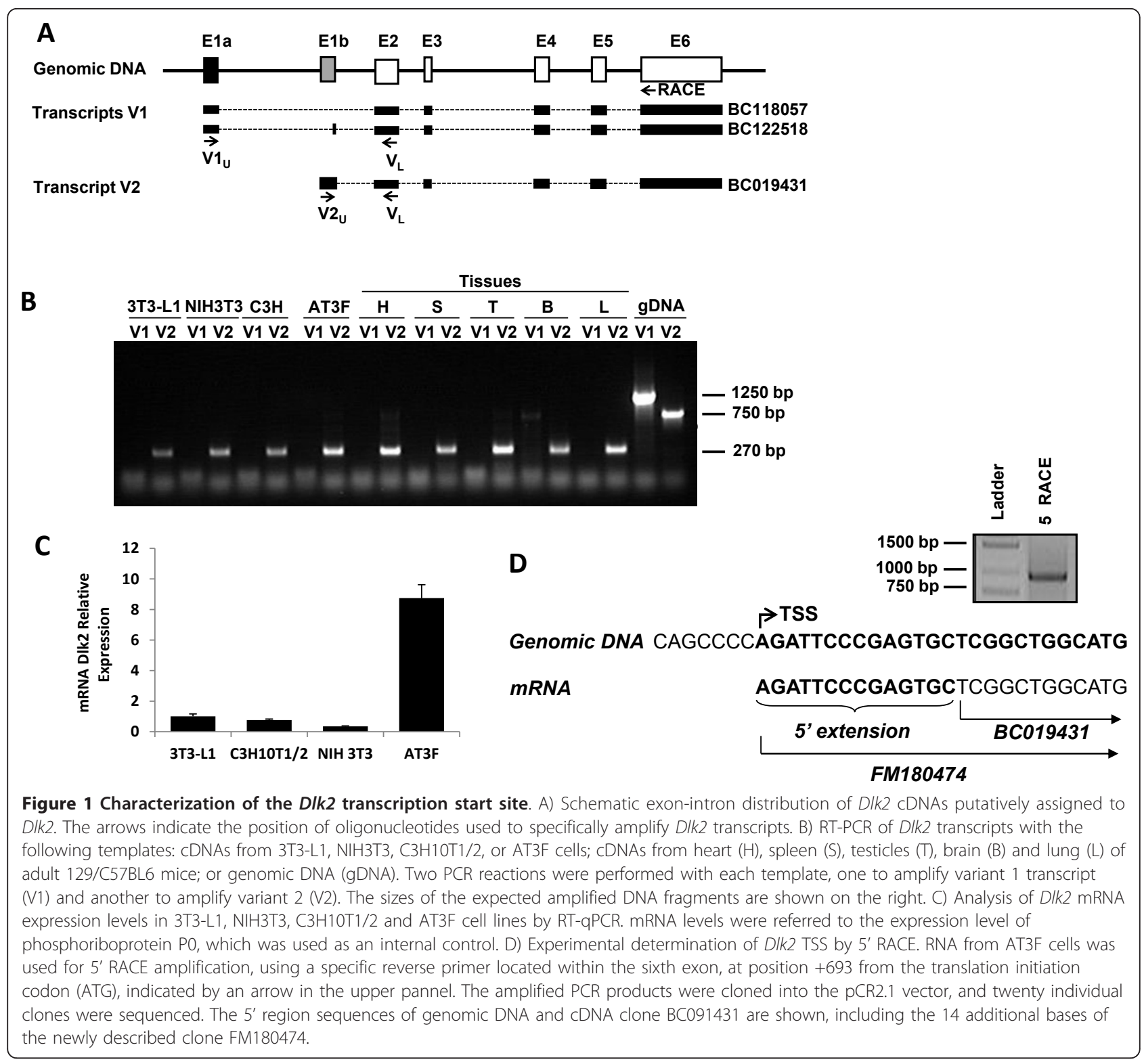

cloned into the vector pCR2.1 (Invitrogen) and twenty independent clones were selected for DNA sequencing. Our sequence data first showed that all clones contained exons that were only compatible with the V2 variant and, therefore, also with the exon-intron distribution of the cDNA clone BC019431 (Figure 1D). In addition, most of the clones (75\%) contained 14 additional bases as a $5^{\prime}$ extension when compared to the sequence of BC019431, and the remaining 25\% contained shorter 5' extensions. The complete Dlk2 mRNA sequence, which starts at an A located 203 bases upstream of the ATG start of protein translation, has been submitted to Genbank with the entry number FM180474 [GenBank: FM180474].
Taken together, our data indicate that in the tissues and cell lines analyzed, the only Dlk2 mRNA species that could be detected is solely compatible with the cDNA clone BC019431 and, at least in the AT3F cell line, that mRNA possesses a 14 bp 5' extension as compared to this clone. Once the TSS was located, our data also suggested that the sequences in charge of controlling $D l k 2$ gene expression were probably placed in the surroundings of exon E1b (Figure 1A).

Transcriptional analysis of the Dlk2 promoter region We decided to analyze the basal transcriptional regulation of the $D l k 2$ promoter region around $1 \mathrm{Kbp}$ upstream of the TSS. To do that, we cloned a 1,090 bp 
DNA fragment spanning from position $-1,090$ to $+1(+1$ corresponds to the TSS) into the pGL3Basic vector. We also made a series of constructs in the same vector, containing different 5' deletions of that fragment (Figure 2). All the constructs were tested for their transcriptional activity by transfecting them into NIH3T3 cells and measuring their corresponding induced luciferase activity. All the luciferase measurements were normalized against the Renilla activity of the pRL-TK vector. Our results showed that the largest fragment, $-1,090 /+1$, displayed a very low transcriptional activity, as it happened also with the first three deletions studied, $-910 /+1,-710 /$ +1 , and $-575 /+1$ (Figure 2). Surprisingly, the maximum luciferase activity of the $D l k 2$ promoter region was obtained with the fragments $-375 /+1$ and $-212 /+1$, corresponding to deletions eliminating most of the $5^{\prime}$ region of the longest fragment, indicating that the core promoter is located within those fragments. To confirm the position of the core promoter, we made an internal deletion in clone $-375 /+1$, in the vicinity of the TSS (positions -197 to -18 ), that we called $-375 /+1 \Delta$. As shown in Figure 2, the internal 179 bp deletion in the $-375 /+1 \Delta$ DNA fragment caused a marked decrease in its basal transcriptional activity. Our data allowed the location of the minimal DNA sequence with promoter activity in the -212 to +1 region, and showed that the sequence located between -197 and -18 plays an important role in the regulation of $D l k 2$ transcription.

The fact that longer DNA fragments showed lower transcriptional activity than shorter fragments suggested the existence of transcriptional inhibitory sequences located between positions $-1,091$ and -375 . To test that hypothesis, we decided to use the pGL3Promoter vector, which shows a higher basal transcriptional activity due to the presence of the strong SV40 promoter. We generated four deletions of the fragment $-1,090 /-375$, which were cloned into pGL3Promoter, and we tested their transcriptional activity in NIH3T3 cells. As shown in Additional file 1, Figure S1, all constructs showed a statistically significant reduction of around 30\% in their luciferase activity when compared to the pGL3Promoter control vector, thus indicating the existence of sequences able to repressing the transcriptional activity of the SV40 promoter. At this stage we decided to check the publically available genomic map of chromatin modifications performed in cells with different degrees of differentiation [30]. In that map, the methylation of certain lysine residues of Histone H3 (K4, K9, $\mathrm{K} 20$ and K27) is mapped, and is correlated with the activity of the promoter. According to that map, $D l k 2$ presents two regions with $\mathrm{H} 3$ methylation corresponding to repressed chromatin: one with exclusive

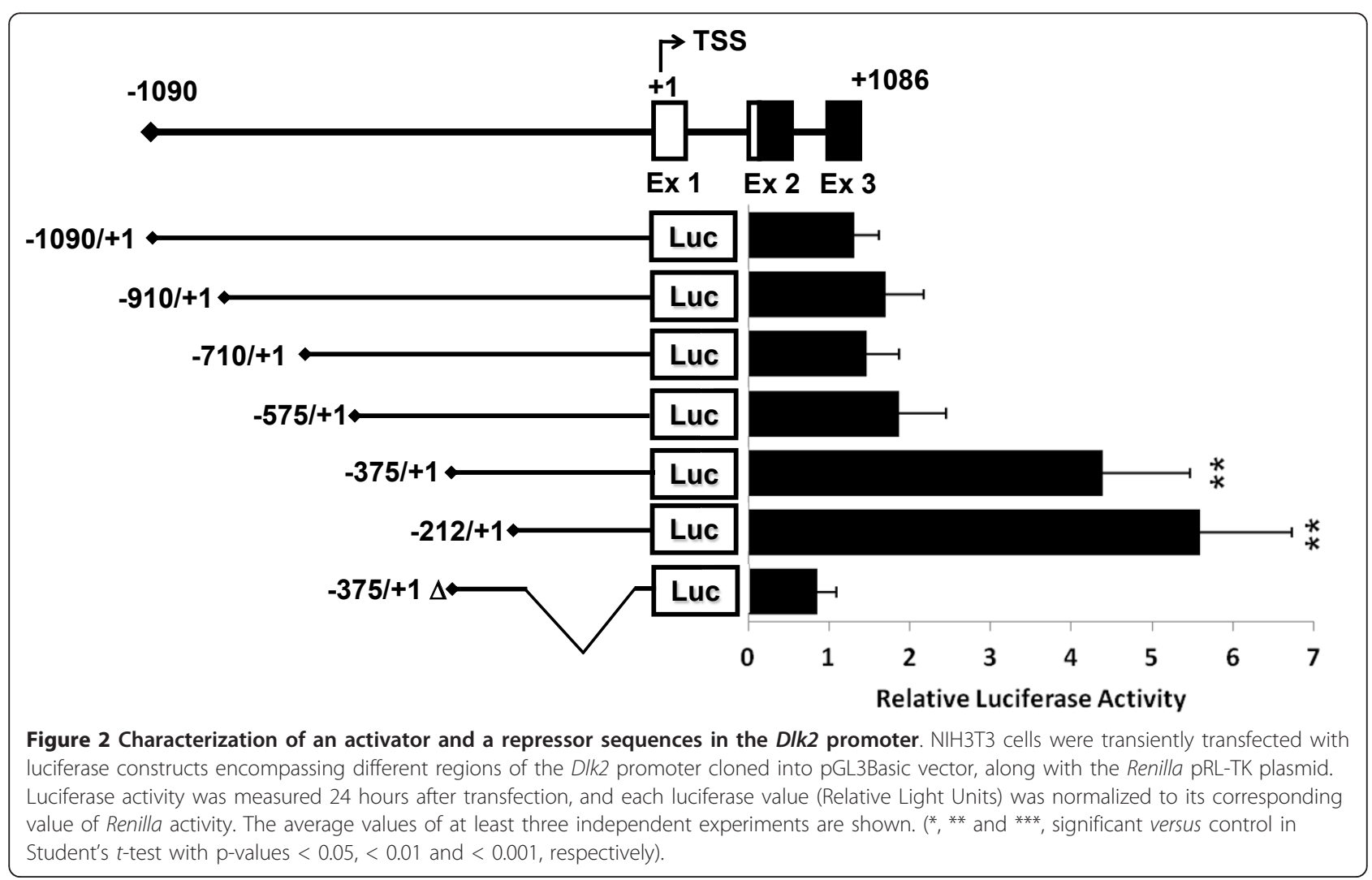


H3K27me3 methylation in the region $-1,502 /-233$, and another one with double methylation H3K27me3 (+484/ $+1232)$ and H3K4me3 $(+382 /+895)$. Interestingly, the inhibitory region we have mapped $(-1,090 /-375)$ is located within the first repressor region cited. Therefore, this first analysis of the $D l k 2$ promoter region allowed us to conclude that the minimal region with transcriptional activity is located between positions -212 and +1 , and that repressor sequences are located between positions $-1,090$ and -375 .

We next performed a bioinformatics analysis of $D l k 2$ promoter region that showed the absence of a consensus TATA box and the existence of a potential Initiator sequence (Inr), YYANWYY (where $\mathrm{Y}$ is a pyrimidine, $\mathrm{N}$ is any nucleotide, and $\mathrm{W}$ is adenine or thymine) [31-33] between the bases -2 and +4 around the TSS. A Downstream Core Promoter Element (DPE), whose consensus sequence is RGWYVT (where $\mathrm{R}$ is a purine, and $\mathrm{V}$ is guanine or adenine or cytosine) [33-35], was also identified in the $D l k 2$ promoter between bases +28 and +33 (Figure 3A). Interestingly, a $\mathrm{CpG}$ island was also detected between positions -481 and +440 , which extends from the putative core promoter to the first intron, including the non-coding first exon (Figure 3B). Therefore, $D l k 2$ appears to be a gene with a TATA-less promoter associated to a $\mathrm{CpG}$ island and, as it happens with other genes with that type of promoter, it also features the presence of GC-boxes. Six GC boxes, potential binding sites for the transcription factor Sp1, were detected in the region close to the TSS, between positions -160 and +90 (Figure 3A). In the absence of a TATA box, Sp1 appears to be involved in the formation of the pre-initiation complex (PIC) and in the transcriptional activation, in conjunction with the Inr element [33,36-39].

The fact that there were putative Sp1 binding sites downstream of the DPE consensus sequence made us consider the idea that transcriptional regulatory regions could be located downstream of the TSS. To explore this, we cloned into pGL3Basic several DNA fragments spanning the region located between bases -212 and +421 , from the start of the core promoter to part of the first intron; those plasmids were transfected into NIH3T3 cells and their transcriptional activity was analyzed (see Methods). DNA fragment $-212 /+177$, which contains the full core promoter region $(-212 /+1)$, the Inr element, the DPE element, and all putative Sp1 binding sites, caused a significant increase in luciferase activity as compared to fragment $-212 /+1$ (Figure 3C). This indicated the presence of additional activating sequences in that region. The transcriptional activity of fragment $-212 /+427$ was very similar to that of fragment -212 / +177 , indicating the absence of additional activating sequences in the part of the first intron located between bases +177 and +427 (Figure $3 \mathrm{C}$ ). Taken together, our data indicate that, although the minimal promoter sequence is located in fragment $-212 /+1$, additional sequences contributing to increase the level of basal transcriptional activity of the $D l k 2$ promoter are present in fragment $+1 /+177$. According to those data, the $D l k 2$ core promoter comprises the Inr and DPE elements, along with several binding sites for the Sp1 transcription factor, located between positions $-160 /-100$ and +52 / +92 .

\section{Sp1 activates the Dlk2 promoter}

To explore whether $\mathrm{Sp} 1$ regulates $D l k 2$ transcription, and which of the six Sp1 putative binding sites could be involved in that process, we co-transfected into NIH3T3 cells different $D l k 2$ promoter-luciferase constructs containing the potential Sp1 binding sites, along with a plasmid expressing Sp1 (pCMVSport-Sp1), or the empty vector (pCMVSport) as a control. To preserve the total amount of DNA transfected into the cells, in these experiments we used half the amount $(0.4 \mu \mathrm{g})$ of reporter plasmid as compared to previous experiments (see Methods). Our results showed that all promoter fragments containing Sp1 binding sites, $-212 /+1,-375 /+1$, $-212 /+177$, and $+1 /+177$, induced luciferase activity when Sp1 was overexpressed (Figure 4A); on the other hand, the fragment $-375 /+1 \Delta$, which lacks any Sp1 binding site, showed no responsiveness to $\mathrm{Sp} 1$.

To analyze the involvement of each GC box in the induction of transcriptional activity, we next mutated each one of them separately in their corresponding fragments, and tested whether the mutations affected the way they responded to Sp1. As shown in Figure 4B, when we analyzed the activity of the mutant Sp1 binding sites located upstream of the TSS (binding sites 1, 2 and 3 ), we could not detect any significant variation in the way the different mutants responded to Sp1. However, mutations of the Sp1 binding sites 4, 5 and 6, located in the $+1 /+177$ fragment, led to a significant reduction of their responses to $\mathrm{Sp} 1$ in all cases (Figure $4 \mathrm{~B})$. Our results demonstrate the existence of functional Sp1 response elements within the first exon of $D l k 2$, and possibly in its proximal promoter, that might transcriptionally regulate the expression of $D l k 2$.

\section{Sp1 specifically binds to the Dlk2 promoter}

To study whether Sp1 directly binds to the $D l k 2$ promoter, we next performed chromatin immunoprecipitation analyses (ChIP) in 3T3-L1 cells with the ChIP-IT Express Kit (Active Motif). We used normal rabbit IgG as a negative control, and antibodies against RNA-polymerase II as a positive immunoprecipitation control. We also performed immunoprecipitation with an antibody against Sp1 (PEP2, Santa Cruz Biotechnology Inc.). 


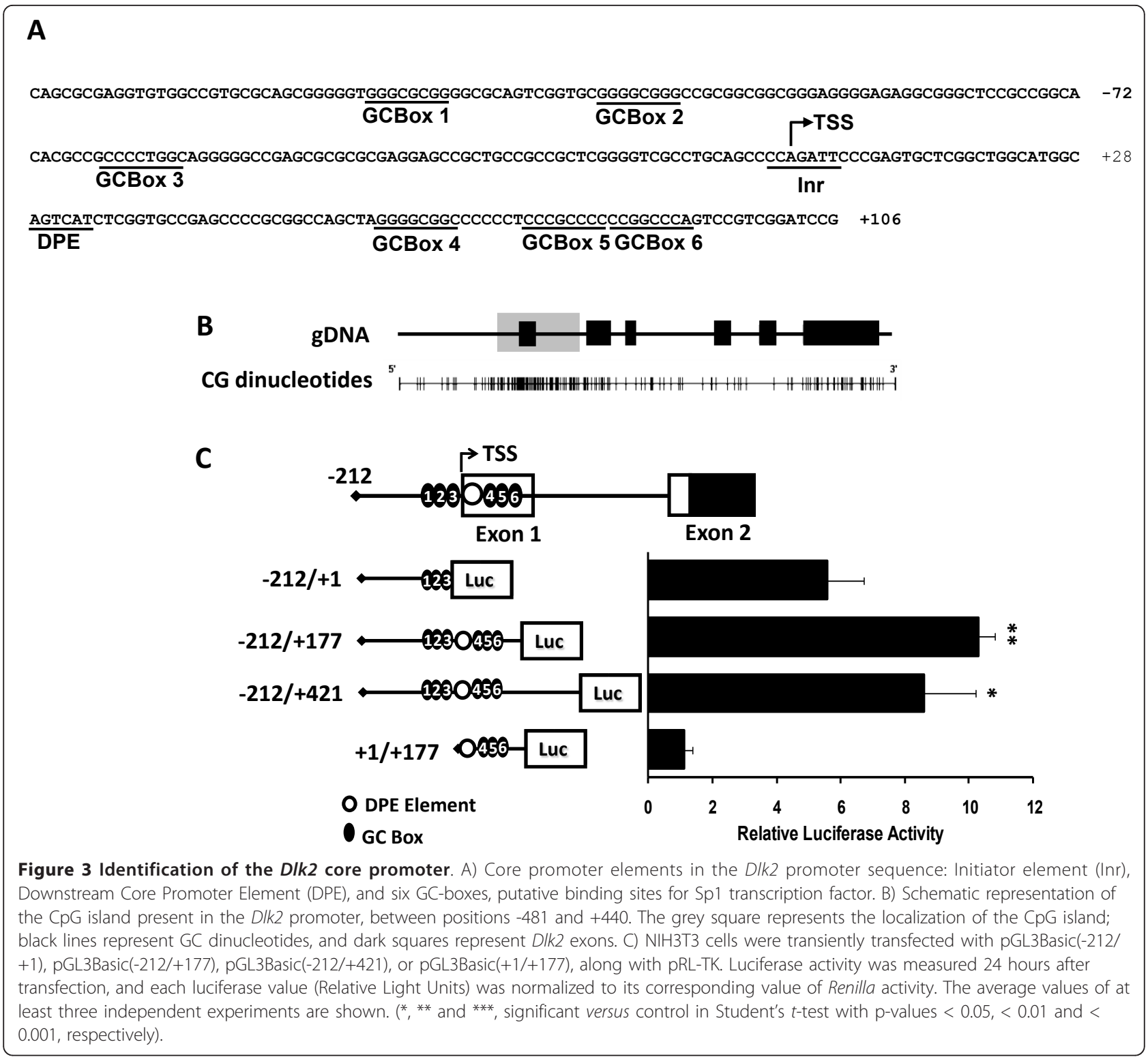

Purified DNA from the immunoprecipitated samples was used as template for PCR, using a pair of primers specific to $D l k 2$ (indicated by arrows in Figure 5A), which amplify the region surrounding the TSS (see Materials and Methods). The results (Figure 5B) indicated that $\mathrm{Sp} 1$ directly binds to the $D l k 2$ promoter region, and suggested that $\mathrm{Sp} 1$ can be directly responsible of the regulation of $D l k 2$ expression reported in previous studies.

To further analyze Sp1 binding to $D l k 2$, we next explored by EMSA which of the six GC-boxes were directly bound by that transcription factor. We designed three double-stranded oligonucleotides, containing one, two or three of the six GC Boxes (Figure $5 \mathrm{~A})$, that were radiolabeled and incubated with nuclear protein extracts from NIH3T3 cells expressing Sp1. Following electrophoresis and autoradiography, we detected the formation of DNA-protein complexes with the three oligonucleotides tested (Figure $5 \mathrm{C}$ and 5D). These complexes appeared to be specific in the case of oligonucleotides Sp1-A and Sp1-C, since they could be competed out both by a 100 -fold excess of the unlabeled oligonucleotide, and by a similar excess of a commercial consensus Sp1 oligonucleotide. In addition, the same commercial oligonucleotide in which the Sp1 consensus site had been mutated was unable to compete with the labeled oligonucleotides. Finally, the addition of a specific antibody against the $\mathrm{Sp} 1$ protein produced a supershift in both cases. We also detected a protein-DNA complex with the Sp1-B 


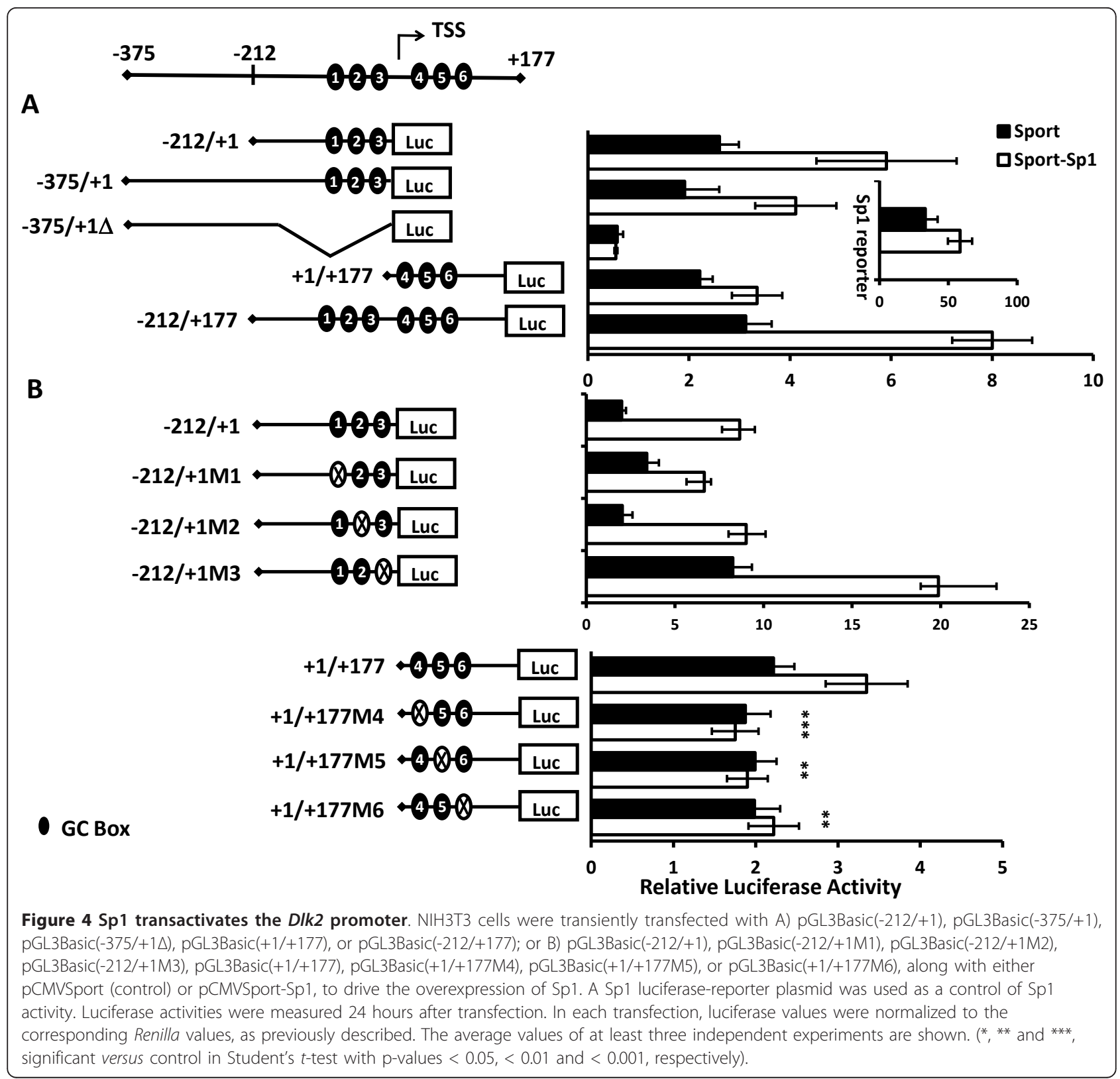

oligonucleotide, but the competition and supershift assays were negative.

As oligonucleotide Sp1-C contains three of the six GC-boxes (4 through 6), we synthesized a series of mutated versions of this oligonucleotide; three of them in which each one of the Sp1 binding sites was individually mutated (oligonucleotides M4, M5 and M6); and one in which the three sites were simultaneously mutated (oligonucleotide MT). When these oligonucleotides were used as binding competitors to Sp1 in EMSA analyses, we found that only MT was unable to block the formation of the Sp1-DNA complex (Figure 5C). The fact that the single mutations did not abolish the competing capacity of each oligonucleotide indicates that Sp1 binds at least to two out of the three GC boxes present in the oligonucleotide Sp1-C.

Our results point to $\mathrm{Sp} 1$ as an important regulator of $D l k 2$ transcription, able to bind to two different regions of the $D l k 2$ promoter, one located between positions -100 and -160 , and the other between positions +52 and +92 .

Downregulation of $\mathrm{Sp} 1$ expression by siRNA results in direct downregulation of Dlk2

To provide additional support about the role of $\mathrm{Sp} 1$ on the regulation of $D l k 2$ expression, we carried out two 


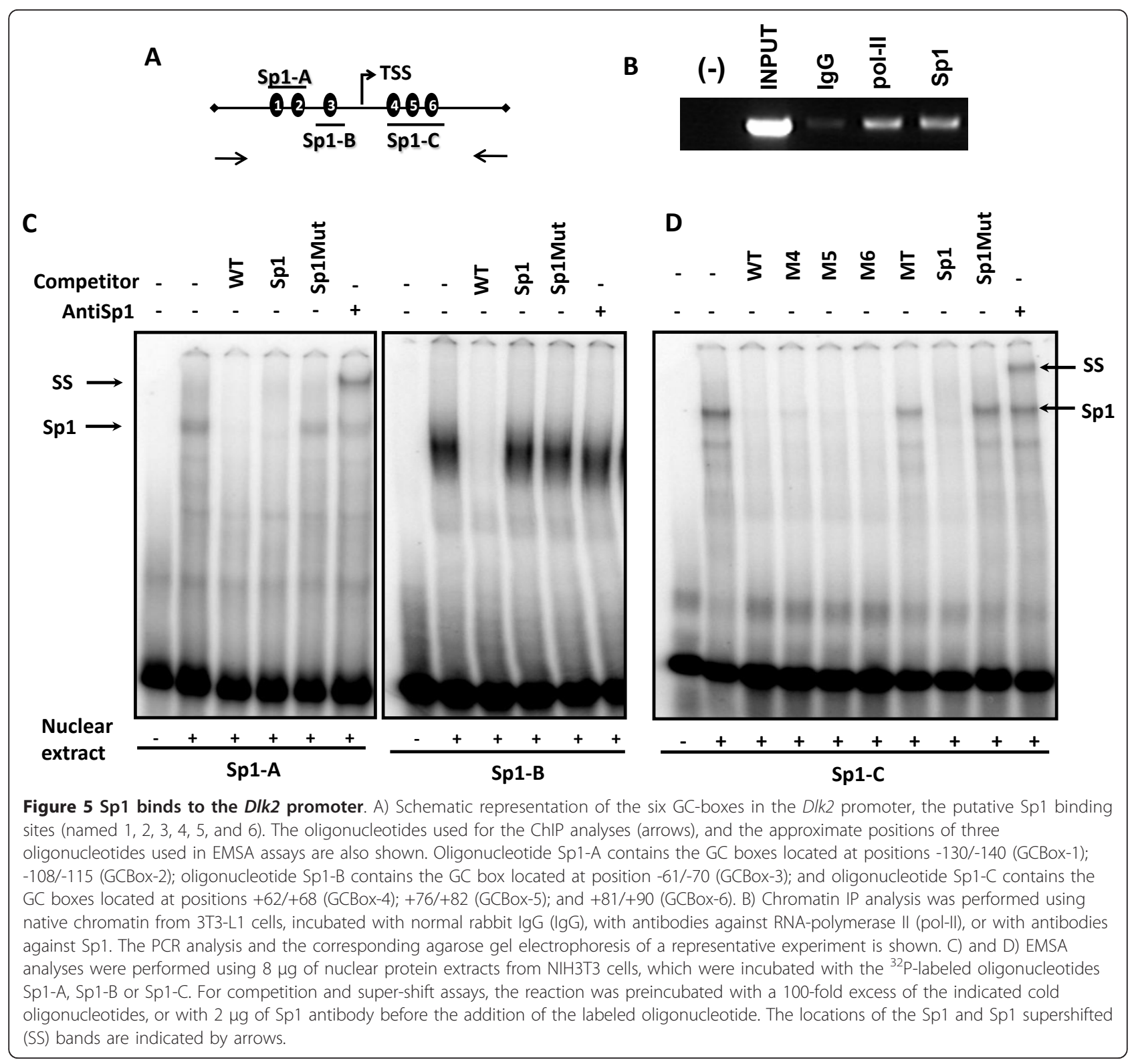

sets of RNA interference experiments. We first analyzed the effect of the downregulation of $S p 1$ on the transcriptional activity of a luciferase reporter plasmid carrying the six putative Sp1 binding sites present in Dlk2 promoter. For that, NIH3T3 cells were transiently co-transfected either with pGL3basic-212/+427, with a Silencer Select siRNA specific to Sp1 (Life Technologies), or with the corresponding negative control, along with the Sp1 expression plasmid, pCMVSport-Sp1, or its corresponding empty vector. As shown in Figure 6A, transfection with $S p 1$ specific siRNA resulted in a reduction of both basal activity, and Sp1 mediated activation of the reporter plasmid, demonstrating the existence of an Sp1 responsive element in the $D l k 2$ promoter.
To fully demonstrate the role of Sp1 in Dlk2 regulation, we next performed transient transfections in NIH3T3 cells, either with the Sp1 siRNA or with its negative control, and analyzed the effects of Sp1 downregulation on Dlk2 transcription by RT-qPCR. As shown in Figure 6B, the reduction of $\mathrm{Sp} 1$ expression resulted in a $50 \%$ reduction in the amount of Dlk 2 mRNA, indicating that $\mathrm{Sp} 1$ plays an important role in the regulation of Dlk2 expression.

\section{Discussion}

The work presented here adds new elements to understanding the biology of $D l k 2$, providing new insights into the molecular mechanisms that contribute to its 
A

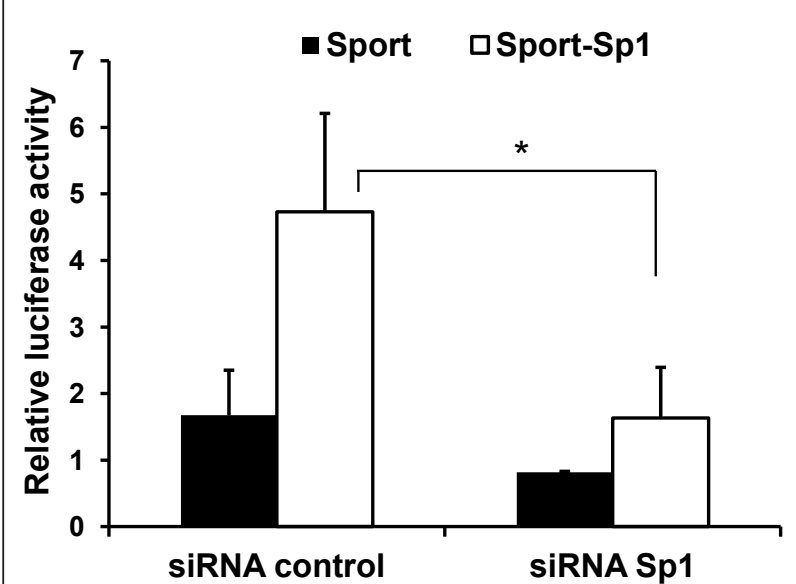

B

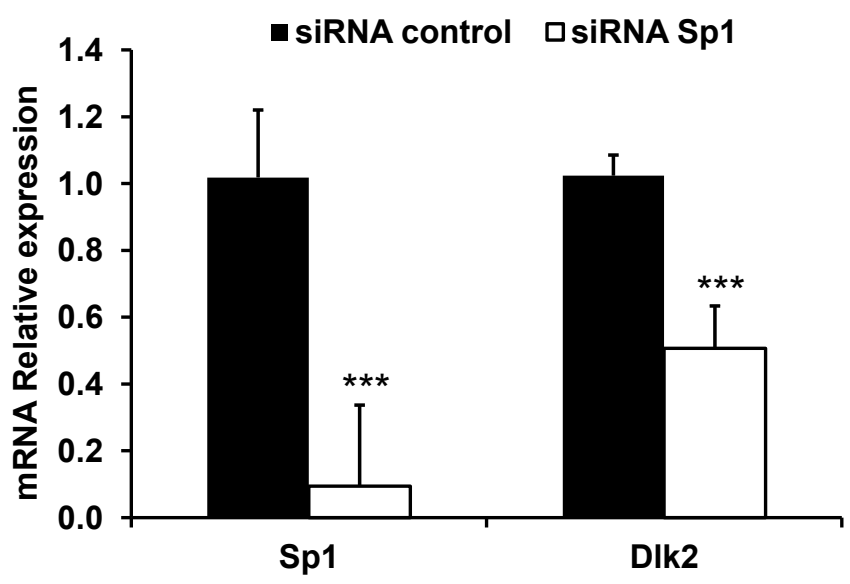

Figure 6 siRNA specific to Sp1 reduces the transcriptional activity of the Dlk2 promoter and the expression of its mRNA. A) NIH3T3 cells were transiently transfected with the luciferase construct pGL3Basic(-212/+427), along with either pCMVSport (control) or pCMVSport-Sp1, to drive the overexpression of Sp1, and with a Sp1 siRNA or its negative control. Luciferase activities were measured 48 hours after transfection. In each transfection, luciferase values were normalized to the corresponding Renilla values, as previously described. B) NIH3T3 cells were transiently transfected with $10 \mathrm{nM}$ of a Sp1-specific siRNA or with the corresponding negative control (Life Technologies). 48 hours after transfection the Sp1 and D/k2 mRNA expression levels were measured by RT-qPCR. mRNA levels were referred to the expression level of phosphoriboprotein P0, used as an internal control, and the normalized values were referred to the values obtained with the negative control. The average values of three independent experiments are shown. $\left(^{*},{ }^{* *}\right.$ and ${ }^{* * *}$, significant versus control in Student's $t$-test with $p$-values $<0.05$, $<0.01$ and $<0.001$, respectively)

expression. The mouse $D l k 2$ genomic locus has been constantly revised during the last years, which has led to frequent changes in the assignment of the corresponding predicted transcripts. At present, the sequence of the mouse $D l k 2$ locus appears as definite, but the number of $D l k 2$ putative transcripts varies among databases. In the RefSeq database, there were three full-length mRNAs associated to Dlk2, BC118057, BC122518, and BC019431. In this work, we have identified, in all tissues and cell lines tested, a unique $D l k 2$ transcript, only compatible with cDNA clone BC019431. Our directed PCR analyses and the results of the RACE assays showed that the TSS identified for $D l k 2$ is only compatible with that transcript (Figure 1B). Our results also show a 14 bp 5' extension of the seemingly truncated BC019431 clone. A new entry taking into consideration our experimental data has been established in GenBank/EMBL/DDBJ databases, with ID FM180474. As mentioned above, the BC019431 entry was temporarily eliminated from the databases, and even today it is still defined as a chimeric clone. However, in the variety of mouse tissues and cell lines used for the characterization of $D l k 2$ transcripts in this work we have reported the existence of a single major $D l k 2$ mRNA species consistent with clone BC019431. Interestingly, we have also detected a minority transcript, yet uncharacterized, that seems to be expressed only in the brain, and that does not correspond to any of de V1 transcripts previously described.
Although we cannot rule out the existence of additional mRNA transcripts expressed in other tissues or at different developmental stages, our data show that clone BC019431, and its extended version, clone FM180474, are clearly non-chimeric mRNAs.

Analysis of the $D l k 2$ promoter transcriptional activity by luciferase assays revealed that the shortest fragment with transcriptional activity is located between positions -212 and +1 , and that the deletion of 179 bp located between positions -194 and -18 led to the complete abolition of $D l k 2$ transcriptional activity (Figure 2). Unexpectedly, the largest fragment tested, $-1,090 /+1$, showed very low transcriptional activity, apparently due to the presence of inhibitory sequences in the region located between -1,090 and -375 bp, as confirmed by luciferase assays performed with strong SV40 promoter constructs. It seems that the $D l k 2$ promoter shows low level of basal transcription, due to the mentioned repressive sequences. We have explored the predicted state of the chromatin at the $D l k 2$ promoter region, taking advantage of the publically available genomic map of chromatin modifications performed in cells with different degrees of differentiation, focused on the methylation of certain lysine residues of these proteins, such as K4, K9, K20 and K27 of Histone H3 [30]. According to this map, $D l k 2$ presents two regions with $\mathrm{H} 3$ methylation, the first one with $\mathrm{H} 3 \mathrm{~K} 27 \mathrm{me} 3$ methylation (region -1,502/-233), in ES cells and in MEFs, and the second 
one with double H3K4me3, H3K27me3 methylation $(+484 /+1232$ and $+382 /+895)$ in ES cells (http://www. ensembl.org). According to the authors of the map, single methylation at residue $\mathrm{K} 4$ is associated with an active chromatin state; however, methylation at residue K27 is a mark of repressed chromatin. Some promoters present simultaneously both H3K4 and H3K27 methylation, and in most of them the basal transcription is repressed [30]. These ambiguous promoters have been associated to genes of complex expression, including cell surface molecules and key transcription factors, during development or morphogenesis. The first H3K27me3 region coincides with the repressor region mapped in our luciferase experiments, and could be in part responsible for the basal repressed state of $D l k 2$, a membrane protein involved in morphogenesis, developmental and differentiation processes [1].

Bioinformatics analyses showed that $D l k 2$ is a TATAless promoter gene, as are about $74 \%$ of human genes $[33,39,40]$. That analysis also revealed the existence of core promoter consensus elements, such as Inr and DPE. Those elements are common in TATA-less promoters: they are required to trigger transcription in the absence of a TATA sequence [31,41]. An important aspect of the $D l k 2$ promoter structure is the presence of a CpG island between positions -481 and +440 , which extends from the putative core promoter to the first intron, including the non-coding first exon. CpG islands are potentially sensitive to DNA-methylation, and could participate in gene transcriptional regulation [42]. The basal state of $\mathrm{CpG}$ islands in the promoters possessing them is non-methylated, although methylation can occur at certain times during development, to achieve specific gene silencing [43-46]. So far, nothing is known about the methylation state of the $D l k 2 \mathrm{CpG}$ island. This issue is, however, of great potential importance for the understanding of the transcriptional regulation of $D l k 2$ during development, and along the differentiation processes in which that gene participates, and is currently under study in our laboratory.

When TATA-less promoters are associated to CpG islands generally they contain consensus GC-boxes in the region close to the TSS that could be recognized by the transcription factor Sp1 [33,47]. It has been reported that, together with the Inr element, $\mathrm{Sp} 1$ can regulate the transcription of those genes $[37,38]$. There are six GCboxes in the $D l k 2$ promoter, located between positions -160 and +90 . We have shown that the transcription factor Sp1 could bind to the Dlk2 promoter in that region, both by ChIP and by EMSA analyses. In addition, our luciferase assays have shown that the activity of the Dlk2 promoter is modulated by Sp1, and that mutation of some of the Sp1 binding sites abolished Sp1-mediated Dlk2 transactivation. We have also demonstrated that a reduction in the expression level of Sp1, using siRNA technology, results in a decrease of the transcriptional activity of the $D l k 2$ promoter, as well as a reduction in the amount of $D l k 2$ mRNA. Our results indicate, therefore, that $\mathrm{Sp} 1$ is a key regulator of Dlk2 transcription.

Interestingly, during in vitro adipogenic assays in 3T3L1 cells, Sp1 expression is reduced in response to some of the components of the adipogenic differentiation cocktail, including IBMX, a cAMP phosphodiesterase inhibitor, and the glucocorticoid dexamethasone. Sp1 has also been involved in the control of transcription of several genes that are essential for the correct onset of adipogenesis; an IBMX-dependent reduction of Sp1 expression causes a derepression of the C/ebpogene, thus promoting adipogenesis [48]. Other authors have recently reported that the Sp1-dependent downregulation of the Tissue Inhibitor of Metalloproteinase 3 (TIMP-3) is necessary for adipogenesis [49]. On the other hand, unpublished data from our group shows that $D l k 2$ is an important factor regulating the early stages of adipogenesis, being a transcriptional target of the crucial transcription factor KLF4. Dlk2 expression is tightly controlled during the first hours of the adipogenic differentiation, showing a peak of expression two hours after the induction with IBMX, and maintaining a low level of expression during the rest of the process. The fact that the expression of both Sp1 and Dlk2 are controlled by the same molecule during early adipogenesis, together with the role of Sp1 in activating the expression of $D l k 2$, raise the interesting possibility that Dlk2 could be a transcriptional target of Sp1 during the adipogenesis process. Finally, we have recently described that together with $D l k 1, D l k 2$ acts as a NOTCH signaling regulator [29]. The control of $D l k 2$ expression, therefore, may be a mechanism with important consequences for the regulation of the numerous differentiation processes in with NOTCH receptors participate. Further studies are granted to explore these possibilities.

\section{Conclusions}

We show here the characterization of the mouse Dlk2 transcript in several preadipocitic and hepatoma cell lines, as well as in adult brain, spleen, heart, liver, and testis. In all the samples the transcript appears as a unique species, with a 14 bases $5^{\prime}$ extension related to the previously described clone BC019431, and it has been entered in GenBank with the ID [GenBank: FM180474]. Dlk2 possesses a TATA-less promoter, with the consensus sequences Inr and DPE, and located within a CpG island. There are sequences able to repress transcription, located at position -1,090/-375 that may in part be responsible for the repressed basal state of the Dlk2 promoter. The minimal sequence with 
transcriptional activity is located between positions -212 and +1 . The $D l k 2$ core promoter contains six GC-boxes between the position -160 and +92 , consensus sequences for the binding of the transcription factor Sp1. We have shown, both by ChIP and by EMSA analyses that $\mathrm{Sp} 1$ binds to the Dlk2 promoter in that region. Additionally, we have demonstrated that the activity of the $D l k 2$ promoter is modulated by $\mathrm{Sp} 1$, and that mutation of some of the Sp1 binding sites abolished Sp1mediated $D l k 2$ transactivation. Our results indicate, therefore, that Sp1 could be a key regulator of $D l k 2$ transcription.

\section{Methods}

\section{DNA constructs}

For the analysis of $D l k 2$ transcriptional activity, we cloned by PCR different fragments of its promoter region, using DNA from BAC clone RP23-135A16 (BACPAC Resources, USA) as template, which contains the complete sequence of the $D l k 2$ promoter, and the oligonucleotides indicated in Table 1. PCR reactions were performed under standard conditions, except where indicated with an asterisk, in which case the reactions were supplemented with 10\% DMSO. The DNA from the PCR amplification was digested with the restriction enzymes indicated in Table 1 , and inserted into the vectors pGL3Basic or pGL3Promoter (Promega, USA). The fragment $-375 /+1 \Delta$ was generated by the amplification of the fragment $-375 /+1$ with the oligonucleotides listed in Table 1 under standard PCR conditions; in the absence of $10 \%$ DMSO, the PCR reaction generated a $196 \mathrm{bp}$ fragment $(-375$ to +1$)$ with a $179 \mathrm{bp}$ internal deletion between positions -197 and -18 . DNA from the PCR amplifications was digested with MluIHindIII, and cloned into the vector pGL3Basic. The mutant luciferase constructs pGL3Basic $(-212 /+1 \mathrm{M} 1)$, pGL3Basic $(-212 /+1 M 2), \quad$ pGL3Basic $(-212 /+1 M 3)$, pGL3Basic(+1/+177M4), pGL3Basic(+1/+177M5), and pGL3Basic $(+1 /+177 \mathrm{M} 6)$, were generated with the Quick-Change site-directed mutagenesis kit (Stratagene,

Table 1 Oligonucleotides used for the cloning of different fragments of Dk/2 promoter in pGL3Basic and pGL3promoter vectors

\begin{tabular}{|c|c|c|c|}
\hline DNA FRAGMENT & OLIGONUCLEOTIDES & SEQUENCE & RESTRICTION ENZYMES \\
\hline \multirow[t]{2}{*}{$-1,090 /+1^{*}$} & Dlk2Mlul-917U & 5'-ATTACGCGTTTGTCAGGTGTAGGCGGTGGG-3' & Mlul-HindIII \\
\hline & Dlk2Hindlll-1L & 5'-TATAAGCTTGCTGAGGCGACCCCGAGCG-3' & \\
\hline \multirow[t]{2}{*}{$-910 /+1^{*}$} & Dlk2Mlul-722U & 5'-GGCGACGCGTCAAATACACATATTGGGGTCTT-3' & Mlul-HindIII \\
\hline & Dlk2HindIII-1L & 5'-TATAAGCTTGCTGAGGCGACCCCGAGCG-3' & \\
\hline \multirow[t]{2}{*}{$-710 /+1^{*}$} & Dlk2Mlul-522U & 5'-TATACGCGTGGCAGGCTACCCAAAGGTGG-3' & Mlul-HindIII \\
\hline & Dlk2HindIII-1L & 5'-TATAAGCTTGCTGAGGCGACCCCGAGCG-3' & \\
\hline \multirow[t]{2}{*}{$-575 /+1^{*}$} & Dlk2Mlul-400U & 5'-TAGACGCGTAAGAAGCCCACAGAGAGCAGGC-3' & Mlul-HindIII \\
\hline & Dlk2Hind|ll-1L & 5'-TATAAGCTTGCTGAGGCGACCCCGAGCG-3' & \\
\hline \multirow[t]{2}{*}{$-375 /+1^{*}$} & Dlk2Mlul-205U & 5'-TATACGCGTTGGGTGAGGGGCAGAGTGG-3' & Mlul-HindIII \\
\hline & Dlk2Hindl|I-1L & 5'-TATAAGCTTGCTGAGGCGACCCCGAGCG-3' & \\
\hline \multirow[t]{2}{*}{$-212 /+1^{*}$} & Dlk2 Xho-212U & 5'-TATCTCGAGGAAGGGAGGGGCGAAGAGC-3' & Xhol-HindllI \\
\hline & Dlk2Hind|l|-1L & 5'-TATAAGCTTGCTGAGGCGACCCCGAGCG-3' & \\
\hline \multirow[t]{2}{*}{$-1,090 /-375$} & Dlk2Mlul-917U & 5'-ATTACGCGTTTGTCAGGTGTAGGCGGTGGG-3' & Mlul-HindIII \\
\hline & Dlk2HindIII-184L & 5'-GCTAAGCTT CCACTCTGCCCCTCACCCAC-3' & \\
\hline \multirow[t]{2}{*}{$-1,090 /-575$} & Dlk2Mlul-917U & 5'-ATTACGCGTTTGTCAGGTGTAGGCGGTGGG-3' & Mlul-HindIII \\
\hline & Dlk2HindIII-379L & 5'-TAGAAGCTTCGCCTGCTCTCTGTGGGCTTC-3' & \\
\hline \multirow[t]{2}{*}{$-910 /-375$} & Dlk2Mlul-722U & 5'-GGCGACGCGTCAAATACACATATTGGGGTCTT-3' & Mlul-HindIII \\
\hline & Dlk2Hindlll-184L & 5'-GCTAAGCTT CCACTCTGCCCCTCACCCAC-3' & \\
\hline \multirow[t]{2}{*}{$-710 /-375$} & Dlk2Mlul-522U & 5'-TATACGCGTGGCAGGCTACCCAAAGGTGG-3' & Mlul-HindIII \\
\hline & Dlk2Hindl|I-184L & 5'-GCTAAGCTT CCACTCTGCCCCTCACCCAC-3' & \\
\hline \multirow[t]{2}{*}{$+1 /+177$} & Dlk2Xho I+1U & 5'-ATTCTCGAGCCCAGATTCCCGAGTGCTCGGC-3' & Xhol-HindIII \\
\hline & Dlk2Hindlll+177L & 5'-ATGAAGCTTAGGGACCGCGTCCTCCTAGCTTC-3' & \\
\hline \multirow[t]{2}{*}{$-212 /+177^{*}$} & Dlk2 Xho-212U & 5'-TATCTCGAGGAAGGGAGGGGCGAAGAGC-3' & Xhol-HindIII \\
\hline & Dlk2Hindlll+177L & 5'-ATGAAGCTTAGGGACCGCGTCCTCCTAGCTTC-3' & \\
\hline \multirow[t]{2}{*}{$-212 /-427^{*}$} & Dlk2 Xho-212U & 5'-TATCTCGAGGAAGGGAGGGGCGAAGAGC-3 & Xhol-HindIII \\
\hline & Dlk2Hindl|I+427L & 5'-AATAAGCTT GTGGCCACCGCGCGGGAAC-3 & \\
\hline
\end{tabular}

PCR reactions were performed under standard conditions (see Materials and Methods), except where indicated with an asterisk, in which the reactions were supplemented with $10 \%$ DMSO. 
USA), using the pGL3Basic $(-212 /+1)$ or pGL3Basic $(+1 /$ +177 ) constructs as templates. The primers used for mutagenesis are indicated in Table 2. All the constructs were sequence-verified, using 0.5 to $1.0 \mu \mathrm{g}$ of each plasmid for sequencing with the ABI PRISM dRhodamine Terminator Cycle Sequencing Ready Reaction Kit (Applied Biosystems, Carlsbad, CA, USA). Sp1 expression plasmid (pCMVSport-Sp1) and Sp1 luciferasereporter plasmid were kindly provided by Dr. Marta Casado-Pinna.

\section{Cell Culture and RT-PCR Analysis}

Mammalian cells were cultured at $37^{\circ} \mathrm{C}$ in a $5 \%(\mathrm{v} / \mathrm{v})$ $\mathrm{CO}_{2}$ humidified atmosphere, in Dulbecco's modified Eagle's medium (DMEM) for 3T3-L1 (ATCC CCL-92.1), C3H10T1/2 (clone 8, ATCC CCL-226) and NIH3T3 (ATCC CRL-1658) cell lines; DMEM-F12 for the AT3F cell line [50]. In all cases, the media contained $10 \%(\mathrm{v} / \mathrm{v})$ fetal bovine serum (FBS, Biowhittaker), $2 \mathrm{mM}$ L-glutamine (Biowhittaker), $1 \mathrm{Unit} / \mathrm{ml}$ penicillin (Biowhittaker), and $1.0 \mu \mathrm{g} / \mathrm{ml}$ streptomycin (Biowhittaker). For RTqPCR analysis, total RNA was isolated from cells using an RNeasy kit (Qiagen Inc., USA), including a DNAse treatment step to remove potential genomic DNA contamination. First-strand cDNA was prepared in a $20 \mu \mathrm{l}$ reaction volume from $1 \mu \mathrm{g}$ of RNA using $0.5 \mu \mathrm{g}$ of oligo $(\mathrm{dT})_{18}$ and the RevertAid ${ }^{\mathrm{TM}} \mathrm{H}$ Minus M-MuLV II reverse transcriptase kit (Fermentas, Spain). Real-time PCR was performed in a final volume of $10 \mu$ l containing $0.3 \mu \mathrm{M}$ of each oligonucleotide, $1 \mu \mathrm{l}$ of cDNA, and the FastStart SYBR Green Master Mix (Applied Biosystem). Reactions were run in triplicate on a 7500 Fast Real-Time PCR System (Applied Biosystems, Carlsbad, CA, USA) with the following conditions: an initial denaturation step at $95^{\circ} \mathrm{C}$ for 20 seconds, and 40 cycles of 3 seconds at $95^{\circ} \mathrm{C}$, followed by 30 seconds at $60^{\circ} \mathrm{C}$. Details of the primer sets used are provided in Additional file 1,
Table S1. Controls for genomic DNA and primer contamination were routinely performed with non-RT or no template PCR reactions, respectively. Dissociation curves were performed for each set of oligonucleotides to check primer specificity and to confirm the presence of a unique PCR product. Results were analyzed using comparative $\mathrm{Ct}$ method using the ribosomal phosphoprotein P0 as a control for amount of cDNA [51]. To estimate PCR efficiencies, standard curves were performed based on 5 serial dilutions of a cDNA stock (a cDNA mixture of all samples collected). Efficiencies (E) were calculated from the slope of curves using the formula $\mathrm{E}=10^{(-1 / \text { slope })}$. The efficiencies of all primer sets were between 95 and 100\%.

For siRNA downregulation of Sp1, we used the Silencer Select siRNA predesigned for $\mathrm{Sp} 1$, and the corresponding negative control (Life Technologies). siRNA were transfected at a concentration of $10 \mathrm{nM}$ into NIH3T3 cells, using Lipofectamine 2000 (Invitrogen). After 48 hours RNA was purified, and RT-qPCR was performed.

\section{Rapid Amplifications of CDNA Ends (RACE)}

To map the 5' end of Dlk2 gene transcript we used SMART RACE cDNA Amplification Kit (Clontech, Mountain View, CA, USA). Total RNA was isolated from the AT3F cell line with RNeasy Kit (Qiagen Inc. Valencia, CA, USA), which was used to synthesize cDNA with the oligonucleotides 5 CDS: $5^{\prime}-(\mathrm{T})_{25} \mathrm{VN}-3$ ' $(\mathrm{N}=\mathrm{A}, \mathrm{C}, \mathrm{G}$ or $\mathrm{T}, \mathrm{V}=\mathrm{A}, \mathrm{G}$ or $\mathrm{C})$, and SMART II A: 5'-AAG CAG TGG TAT CAA CGC AGA GTA CGC GGG-3'. The cDNA was used as a template for PCR, using the primers UPM (Universal Prime Mix): 5'-CTA ATA CGA CTC ACT ATA GGG CAA GCA GTG GTA TCA ACG CAG AGT-3' and 5'RACEDlk2: 5'CTG GCA TGG GCG GCT GGC ACA GTC ATC CA3'. The amplified DNA fragments were cloned into the

Table 2 Oligonucleotides used for the mutations of Dlk2 GC-boxes

\begin{tabular}{|c|c|c|}
\hline PLASMID & OLIGONUCLEOTIDES & SEQUENCE \\
\hline \multirow[t]{2}{*}{ pGL3Basic(-212/+1M1) } & Sp1212/1M1F & 5'- GTGCGCAGCGGGGGTGGATATAAGGCGCAGTCGGTGCGGG -3 \\
\hline & Sp1212/1M1R & 5'- CCCGCACCGACTGCGCCTTATATCCACCCCCGCTGCGCAC -3' \\
\hline \multirow[t]{2}{*}{ pGL3Basic(-212/+1M2) } & Sp1212/1M2F & 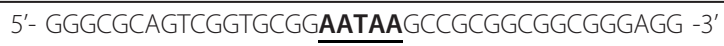 \\
\hline & Sp1212/1M2R & 5'- CCTCCCGCCGCCGCGGCTTATTCCGCACCGACTGCGCCC -3' \\
\hline \multirow[t]{2}{*}{ pGL3Basic(-212/+1M3) } & Sp1212/1M3F & 5'- GGCTCCGCCGGCACACGITATTCCTGGCAGGGGGCCGAG -3' \\
\hline & Sp1212/1M3R & 5'- CTCGGCCCCCTGCCAGGAATAACGTGTGCCGGCGGAGCC -3' \\
\hline \multirow[t]{2}{*}{ pGL3Basic(+1/+177M4) } & Dlk2Mlul-400U & 5'- CCCGCGGCCAGCTAGGTTATTCCCCCCTCCCGCCCCC -3' \\
\hline & Dlk2HindIII-1L & 5'- GGGGGCGGGAGGGGGGAATAACCTAGCTGGCCGCGGG -3' \\
\hline \multirow[t]{2}{*}{ pGL3Basic(+1/+177M5) } & Dlk2Mlul-205U & 5'- AGGGGCGGCCCCCCTCAATAACCCGGCCCACGTCCGTC -3' \\
\hline & Dlk2HindIII-1L & 5'- GACGGACGTGGGCCGGGTTATTGAGGGGGGCCGCCCCT -3' \\
\hline \multirow[t]{2}{*}{ pGL3Basic(+1/+177M6) } & Dlk2 Xho-212U & 5'-GCCCCCCTCCCGCCCCAATTAACAGTCCGTCGGATCCG-3' \\
\hline & Dlk2HindIII-1L & 5'- CGGATCCGACGGACTGTTAATTGGGGCGGGAGGGGGGCC -3' \\
\hline
\end{tabular}


vector pCR2.1 (Invitrogen, CA, USA) and 20 clones were sequenced with the oligonucleotide 5'-TAA CCC GGG GGA TCC ACC AGT GAC CAA GGA-3'.

\section{Analysis of Dlk2 mRNA transcripts}

To analyze the expression of Dlk2 mRNA transcripts, total RNA was isolated from heart, spleen, testis, brain, and lung of adult 129/C57BL6 mice, using the reagent TRI-Reagent (Sigma, USA), according to manufacturer's instructions. The isolated RNA was purified with the RNeasy Kit (Qiagen Inc. Valencia, CA, USA). Total RNA was also isolated from 3T3-L1, NIH3T3, C3H10T1/2 and AT3F cell lines with the RNeasy kit. cDNA was synthesized from $1.0 \mu \mathrm{g}$ of total RNA, using the "Reverse H Minus First Strand cDNA Synthesis kit (Fermentas, Spain). These cDNAs were used as templates in PCR reactions under the following conditions: an initial denaturation step at $95^{\circ} \mathrm{C}$ for 5 minutes, and 45 cycles of 30 seconds at $95^{\circ} \mathrm{C}$, followed by 30 seconds at $58^{\circ} \mathrm{C}$ and 120 seconds at $72^{\circ} \mathrm{C}$. The primers used were: V1 $1_{\mathrm{U}}$ : GGA GAG CCG GGA AAG GCT AAT G; V2 $2_{\mathrm{U}}$ : TCG GCT GGC ATG GCA GCT ACT T; and $\mathrm{V}_{\mathrm{L}}$ : TCA CAC AGC GCT CAC AGT GCA G.

\section{Luciferase reporter assays}

NIH3T3 cells at $80-90 \%$ confluence were plated in 24well plates and transfected using Fu-gene HD reagent (Roche Applied Science, USA). In the experiments performed only with the luciferase reporter plasmids, 0.8 $\mu \mathrm{g}$ of DNA per well were used. However, in the experiments where the luciferase plasmids were transfected along with the Sp1 expression plasmid or the corresponding empty vector, $0.4 \mu \mathrm{g}$ of each plasmid were used. The pRL-TK (Promega, USA), carrying the Renilla luciferase under the control of the thymidine kinase promoter, was also co-transfected as an internal control for transfection efficiency. Cells were harvested 24 hours after transfection and luciferase activities were analyzed using the Dual-Luciferase assay kit (Promega, USA) and MLX Microtiter Plate Luminometer (Dynex Technologies, USA), as recommended by the manufacturer. Luciferase activity was normalized to the Renilla activity measured in the same lysate.

\section{Chromatin immunoprecipitation (ChIP) assays}

ChIP analysis of 3T3-L1 cells was performed using ChIP-IT Express Kit (Active Motif, USA), following the manufacturer's recommendations. Twenty million 3T3L1 cells were formaldehyde-cross-linked, and DNA was sheared by sonication using a Bioruptor Sonication System (Diagenode, Belgium) for 30 minutes. The sheared chromatin was incubated with $3 \mu \mathrm{g}$ of normal rabbit IgG, or the corresponding antibodies against RNA-polymerase II, and Sp1 (PEP2) (Santa Cruz Biotechnology Inc., USA). IPs were performed with the magnetic beads included in the ChIP-IT Express kit. For PCR, $5 \mu \mathrm{l}$ of the $100 \mu \mathrm{l}$ total immunoprecipitated DNA were analyzed using GC-Rich PCR system (Roche Applied Science, USA), with the oligonucleotides Dlk2MluI212U, 5'-TAT ACG CGT GAA GGG AGG GGC GAA

Table 3 Oligonucleotides used for EMSA

\begin{tabular}{|c|c|c|}
\hline \multicolumn{2}{|c|}{ OLIGONUCLEOTIDE } & \multirow{2}{*}{$\begin{array}{c}\text { SEQUENCE } \\
\text { 5-GCTCCGCCGGCACACGCCGCCCCTGGCAGGGGGCCGAGCGC-3 }\end{array}$} \\
\hline Sp1-A & Sp1-As & \\
\hline & Sp1-Aas & 5-GCGCTCGGCCCCCTGCCAGGGGCGGCGTGTGCCGGCGGAGC-3 \\
\hline \multirow[t]{2}{*}{$S p 1-B$} & Sp1-Bs & 5-TGCGCAGCGGGGGTGGGCGCGGGGCGCAGTCGGTGCGGGGCGGGCCGCGGCGGCGGGAGG-3 \\
\hline & Sp1-Bas & 5-CCTCCCGCCGCCGCGGCCCGCCCCGCACCGACTGCGCCCCGCGCCCACCCCCGCTGCGCA-3 \\
\hline \multirow[t]{2}{*}{ Sp1-C } & Sp1-Cs & 5-GGCCAGCTAGGGGCGGCCCCCCTCCCGCCCCCCGGCCCAG-3 \\
\hline & Sp1-Cas & 5-GTGGGCCGGGGGGCGGGAGGGGGGCCGCCCCTAGCTGGCC-3 \\
\hline \multirow[t]{2}{*}{ M4 } & M4s & 5-GGCCAGCTAGTTTATTCCCCCCTCCCGCCCCCCGGCCCAG-3 \\
\hline & M4as & 5-CTGGGCCGGGGGGCGGGAGGGGGGAATAAACTAGCTGGCC-3 \\
\hline \multirow[t]{2}{*}{ M5 } & M5s & 5-GGCCAGCTAGGGGCGGCCCCCCTAAATAACCCCGGCCCAG-3 \\
\hline & M5as & 5-CTGGGCCGGGGTTATTTAGGGGGGCCGCCCCTAGCTGGCC-3 \\
\hline \multirow[t]{2}{*}{ M6 } & M6s & 5-GGCCAGCTAGGGGCGGCCCCCCTCCCGCCCCAATTAAAAG-3 \\
\hline & M6as & 5-CTITAATTGGGGCGGGAGGGGGGCCGCCCCTAGCTGGCC-3 \\
\hline \multirow[t]{2}{*}{ MT } & MTs & 5-GGCCAGCTAGTTTATTCCCCCCTAAATAACCAATTAAAAG-3 \\
\hline & MTas & 5-CTTTAATTGGTTATTTAGGGGGGAATAAACTAGCTGGCC-3 \\
\hline \multirow[t]{2}{*}{$\overline{S p 1}$} & Sp1s & 5-ATTCGATCGGGGCGGGGCGAGC -3 \\
\hline & Sp1as & 3-TAAGCTAGCCCCGCCCCGCTCG-5 \\
\hline \multirow[t]{2}{*}{ Sp1Mut } & Sp1Muts & 5-ATTCGATCGGTTCGGGGCGAG C-3 \\
\hline & Sp1Mutas & 3-TAA GCTAGCCAAGCCCCGCTCG-5 \\
\hline
\end{tabular}

Sp1 consensus (Sp1) and Sp1 mutant consensus (Sp1Mut) oligonucleotides were purchased from Santa Cruz Biotechnologies. 


\section{GAG C-3' and Dlk2HindIII+177L, 5' - ATG AAG CTT AGG GAC CGC GTC CTC CTA GCT TC-3'.}

\section{Nuclear extracts and electrophoretic mobility shift assay} For nuclear extracts NIH3T3 cells were washed twice with ice-cold PBS, then scraped and homogenized for $15 \mathrm{~min}$. on ice with hypotonic lysis buffer $(10 \mathrm{mM}$ Hepes, $\mathrm{pH} 8.0 ; 10 \mathrm{mM} \mathrm{KCl}$, and $1.0 \mu \mathrm{g} / \mu \mathrm{l}$ protease inhibitor cocktail from Sigma, USA). IGEPAL (0.5\%) was added and the mixture was vortexed for 30 seconds at $4^{\circ} \mathrm{C}$, followed by centrifugation at 13,500 r.p.m. for 30 seconds. The nuclear pellets were incubated and vortexed for $30 \mathrm{~min}$. at $4^{\circ} \mathrm{C}$ with $20 \mathrm{mM}$ HEPES, pH 8.0, $0.4 \mathrm{M} \mathrm{NaCl}, 20 \%$ glycerol and $1.0 \mu \mathrm{g} / \mu \mathrm{l}$ of the protease inhibitor cocktail. The samples were centrifuged at 13,500 r.p.m. for 10 min., and the supernatants, containing the nuclear fraction, were collected. EMSA was performed by incubating $8 \mu \mathrm{g}$ of nuclear extracts in a $20 \mu \mathrm{l}$ binding reaction mixture containing $10 \mathrm{mM}$ HEPES $\mathrm{pH}$ 8.0, $80 \mathrm{mM} \mathrm{KCl,} 1 \mathrm{mM}$ DTT, 5\% glycerol, $0.1 \mu \mathrm{g} / \mu \mathrm{l}$ BSA, $0.4 \mathrm{mM} \mathrm{MgCl}_{2}, 2 \mu \mathrm{M} \mathrm{ZnSO}_{4}, 0.02 \%$ IGEPAL, $1 \mu \mathrm{g}$ poly (dI-dC), and 40,000 cpm of ${ }^{32} \mathrm{P}$-labeled doublestranded DNA probe for $20 \mathrm{~min}$. at room temperature. Following incubation, reaction mixtures were loaded and electrophoresed on a $6 \%$ polyacrylamide gel, and subjected to autoradiography. A 100-fold molar excess of unlabeled probe was added for competition when indicated in the corresponding figures. Sp1 and Sp1 mutant oligonucleotides were purchased from Santa Cruz Biotechnology. For competition and supershift experiments, proteins were preincubated with unlabeled probe or with the anti-Sp1 antibody (Sp1(PEP-2), Santa Cruz Biotechnology) for 1 hour at $4^{\circ} \mathrm{C}$. Labeled probe was then added, and incubated for $20 \mathrm{~min}$. at room temperature. Gel shift assay oligonucleotide sequences are indicated in Table 3.

\section{Additional material}

Additional file 1: Table S1. Primers used for RT-qPCR assays. Figure S1. Characterization of a repressor sequence in the DIk2 promoter.

\begin{abstract}
Acknowledgements
We greatly appreciate the technical input offered by Dr. Marta Casado, as well as the kind gift of the Sp1 expression and response plasmids. We thank Dr. Paloma Martín-Sanz for kindly providing us with AT3F cells. We greatly appreciate the help of Dr. Elena de la Casa-Esperón in critically reading the manuscript. The work was supported by Fundación para la Investigación Sanitaria de Castilla-La Mancha, [FISCAM PI-2006/12], and the Spanish Ministry for Science and Education [BFU2007-61094].
\end{abstract}

\section{Author details}

${ }^{1}$ Facultad de Medicina/Centro Regional de Investigaciones Biomédicas (CRIB), Universidad de Castilla-La Mancha. Calle Almansa 14. 02006 Albacete. Spain. ${ }^{2}$ Samuel Rivero. Molecular Pathology Section. Laboratory of Immunogenetics.
National Institute of Allergy and Infectious Diseases, NIH. Twinbrook Building I, Room 1524. 5640 Fisher Lane. Rockville, MD 20852, USA.

\section{Authors' contributions}

SR carried out the molecular analysis of the promoter, the luciferase assays and the EMSAs, and helped to draft the manuscript. ARG participated in the Sp1 luciferase studies. MJMDG participated in the EMSAs and helped with the design of the study. $J$ initiated and participated in the design of the study and helped to draft the manuscript. JJGR conceived the study, carried out the ChIP analysis and the siRNA studies, designed and coordinated most of the experiments and helped to draft the manuscript. All authors read and approved the final manuscript.

Received: 20 July 2011 Accepted: 20 December 2011

Published: 20 December 2011

\section{References}

1. Nueda ML, Baladrón V, García-Ramírez JJ, Sánchez-Solana B, Ruvira MD, Rivero S, Ballesteros MA, Monsalve EM, Díaz-Guerra MJ, Ruiz-Hidalgo MJ, et al: The novel gene EGFL9/Dlk2, highly homologous to Dlk1, functions as a modulator of adipogenesis. J Mol Biol 2007, 367(5):1270-1280.

2. Bauer SR, Ruiz-Hidalgo MJ, Rudikoff EK, Goldstein J, Laborda J: Modulated expression of the epidermal growth factor-like homeotic protein dlk influences stromal-cell-pre-B-cell interactions, stromal cell adipogenesis, and pre-B-cell interleukin-7 requirements. Mol Cell Biol 1998, 18(9):5247-5255.

3. Smas CM, Kachinskas D, Liu CM, Xie X, Dircks LK, Sul HS: Transcriptional control of the pref-1 gene in 3T3-L1 adipocyte differentiation. Sequence requirement for differentiation-dependent suppression. J Biol Chem 1998, 273(48):31751-31758.

4. Smas CM, Sul HS: Pref-1, a protein containing EGF-like repeats, inhibits adipocyte differentiation. Cell 1993, 73(4):725-734

5. Garcés C, Ruiz-Hidalgo MJ, Bonvini E, Goldstein J, Laborda J: Adipocyte differentiation is modulated by secreted delta-like (dlk) variants and requires the expression of membrane-associated dlk. Differentiation 1999, 64(2):103-114

6. Lee K, Villena JA, Moon YS, Kim KH, Lee S, Kang C, Sul HS: Inhibition of adipogenesis and development of glucose intolerance by soluble preadipocyte factor-1 (Pref-1). J Clin Invest 2003, 111(4):453-461.

7. Tanimizu N, Nishikawa M, Saito H, Tsujimura T, Miyajima A: Isolation of hepatoblasts based on the expression of Dlk/Pref-1. J Cell Sci 2003, 116(Pt 9):1775-1786.

8. Tanimizu N, Tsujimura T, Takahide K, Kodama T, Nakamura K, Miyajima A Expression of Dlk/Pref-1 defines a subpopulation in the oval cell compartment of rat liver. Gene Expr Patterns 2004, 5(2):209-218.

9. Raghunandan R, Ruiz-Hidalgo M, Jia Y, Ettinger R, Rudikoff E, Riggins $P$, Farnsworth R, Tesfaye A, Laborda J, Bauer SR: DIk1 influences differentiation and function of B lymphocytes. Stem Cells Dev 2008, 17(3):495-507.

10. Ohno N, Izawa A, Hattori M, Kageyama R, Sudo T: dlk inhibits stem cell factor-induced colony formation of murine hematopoietic progenitors: Hes-1-independent effect. Stem Cells 2001, 19(1):71-79.

11. Kaneta M, Osawa M, Sudo K, Nakauchi H, Farr AG, Takahama Y: A role for pref-1 and HES-1 in thymocyte development. J Immunol 2000, 164(1):256-264.

12. Sakajiri S, O'Kelly J, Yin D, Miller CW, Hofmann WK, Oshimi K, Shih LY, Kim KH, Sul HS, Jensen $\mathrm{CH}$, et al: Dlk1 in normal and abnormal hematopoiesis. Leukemia 2005, 19(8):1404-1410.

13. Moore KA, Pytowski B, Witte L, Hicklin D, Lemischka IR: Hematopoietic activity of a stromal cell transmembrane protein containing epidermal growth factor-like repeat motifs. Proc Natl Acad Sci USA 1997, 94(8):4011-4016.

14. Langer F, Stickel J, Tessema M, Kreipe H, Lehmann U: Overexpression of delta-like (Dlk) in a subset of myelodysplastic syndrome bone marrow trephines. Leuk Res 2004, 28(10):1081-1083.

15. Abdallah BM, Ding $M$, Jensen $C H$, Ditzel N, Flyvbjerg $A$, Jensen $T G$, Dagnaes-Hansen F, Gasser JA, Kassem M: Dlk1/FA1 is a novel endocrine regulator of bone and fat mass and its serum level is modulated by growth hormone. Endocrinology 2007, 148(7):3111-3121.

16. Abdallah BM, Boissy P, Tan Q, Dahlgaard J, Traustadottir GA, Kupisiewicz K Laborda J, Delaisse JM, Kassem M: dlk1/FA1 regulates the function of 
human bone marrow mesenchymal stem cells by modulating gene expression of pro-inflammatory cytokines and immune response-related factors. J Biol Chem 2007, 282(10):7339-7351.

17. Abdallah $B M$, Jensen $C H$, Gutierrez $G$, Leslie RG, Jensen $T G$, Kassem $M$ : Regulation of human skeletal stem cells differentiation by Dlk1/Pref-1. J Bone Miner Res 2004, 19(5):841-852.

18. Halder SK, Takemori H, Hatano O, Nonaka Y, Wada A, Okamoto M: Cloning of a membrane-spanning protein with epidermal growth factor-like repeat motifs from adrenal glomerulosa cells. Endocrinology 1998, 139(7):3316-3328.

19. Okamoto M, Takemori H, Halder SK, Nonaka Y, Hatano O: Implication of ZOG protein (zona glomerulosa-specific protein) in zone development of the adrenal cortex. Endocr Res 1998, 24(3-4):515-520.

20. Raza FS, Puddefoot JR, Vinson GP: Pref-1, SF-1 and adrenocortical zonation. Endocr Res 1998, 24(3-4):977-981.

21. Van Limpt VA, Chan AJ, Van Sluis PG, Caron HN, Van Noesel CJ, Versteeg R: High delta-like 1 expression in a subset of neuroblastoma cell lines corresponds to a differentiated chromaffin cell type. Int I Cancer 2003, 105(1):61-69.

22. Jensen CH, Meyer M, Schroder HD, Kliem A, Zimmer J, Teisner B: Neurons in the monoaminergic nuclei of the rat and human central nervous system express FA1/dlk. Neuroreport 2001, 12(18):3959-3963.

23. Floridon $C$, Jensen $C H$, Thorsen $P$, Nielsen $O$, Sunde L, Westergaard JG, Thomsen SG, Teisner B: Does fetal antigen 1 (FA1) identify cells with regenerative, endocrine and neuroendocrine potentials? A study of FA1 in embryonic, fetal, and placental tissue and in maternal circulation. Differentiation 2000, 66(1):49-59.

24. Costaglioli P, Come C, Knoll-Gellida A, Salles J, Cassagne C, Garbay B: The homeotic protein dlk is expressed during peripheral nerve development. FEBS Lett 2001, 509(3):413-416.

25. Baladrón V, Ruiz-Hidalgo MJ, Gubina E, Bonvini E, Laborda J: Specific regions of the extracellular domain of dlk, an EGF-like homeotic protein involved in differentiation, participate in intramolecular interactions. Front Biosci 2001, 6:A25-32.

26. Laborda J: The role of the epidermal growth factor-like protein dlk in cell differentiation. Histol Histopathol 2000, 15(1):119-129.

27. van Limpt V, Chan A, Caron H, Sluis PV, Boon K, Hermus MC, Versteeg R: SAGE analysis of neuroblastoma reveals a high expression of the human homologue of the Drosophila Delta gene. Med Pediatr Oncol 2000, 35(6):554-558.

28. Samulewicz SJ, Seitz A, Clark L, Heber-Katz E: Expression of preadipocyte factor-1(Pref-1), a delta-like protein, in healing mouse ears. Wound Repair Regen 2002, 10(4):215-221.

29. Sánchez-Solana B, Nueda ML, Ruvira MD, Ruiz-Hidalgo MJ, Monsalve EM, Rivero S, García-Ramírez JJ, Díaz-Guerra MJ, Baladrón V, Laborda J: The EGFlike proteins DLK1 and DLK2 function as inhibitory non-canonical ligands of NOTCH1 receptor that modulate each other's activities. Biochim Biophys Acta 2011, 1813(6):1153-1164.

30. Mikkelsen TS, Ku M, Jaffe DB, Issac B, Lieberman E, Giannoukos G, Alvarez P, Brockman W, Kim TK, Koche RP, et al: Genome-wide maps of chromatin state in pluripotent and lineage-committed cells. Nature 2007, 448(7153):553-560

31. Butler JE, Kadonaga JT: The RNA polymerase II core promoter: a key component in the regulation of gene expression. Genes Dev 2002, 16(20):2583-2592.

32. Corden J, Wasylyk B, Buchwalder A, Sassone-Corsi P, Kedinger C, Chambon P: Promoter sequences of eukaryotic protein-coding genes. Science 1980, 209(4463):1406-1414.

33. Smale ST, Kadonaga JT: The RNA polymerase II core promoter. Annu Rev Biochem 2003, 72:449-479.

34. Juven-Gershon T, Hsu JY, Theisen JW, Kadonaga JT: The RNA polymerase II core promoter - the gateway to transcription. Curr Opin Cell Biol 2008, 20(3):253-259.

35. Kutach AK, Kadonaga JT: The downstream promoter element DPE appears to be as widely used as the TATA box in Drosophila core promoters. Mol Cell Biol 2000, 20(13):4754-4764.

36. Blake MC, Jambou RC, Swick AG, Kahn JW, Azizkhan JC: Transcriptional initiation is controlled by upstream GC-box interactions in a TATAA-less promoter. Mol Cell Biol 1990, 10(12):6632-6641

37. Smale ST, Baltimore D: The "initiator" as a transcription control element. Cell 1989, 57(1):103-113.
38. Smale ST, Schmidt MC, Berk AJ, Baltimore D: Transcriptional activation by Sp1 as directed through TATA or initiator: specific requirement for mammalian transcription factor IID. Proc Natl Acad Sci USA 1990, 87(12):4509-4513.

39. Yang C, Bolotin E, Jiang T, Sladek FM, Martinez E: Prevalence of the initiator over the TATA box in human and yeast genes and identification of DNA motifs enriched in human TATA-less core promoters. Gene 2007, 389(1):52-65.

40. Breathnach R, Chambon P: Organization and expression of eucaryotic split genes coding for proteins. Annu Rev Biochem 1981, 50:349-383.

41. Burke TW, Kadonaga JT: Drosophila TFIID binds to a conserved downstream basal promoter element that is present in many TATA-boxdeficient promoters. Genes Dev 1996, 10(6):711-724.

42. Maston GA, Evans SK, Green MR: Transcriptional regulatory elements in the human genome. Annu Rev Genomics Hum Genet 2006, 7:29-59.

43. Antequera $\mathrm{F}$, Bird $\mathrm{A}$ : Number of $\mathrm{CpG}$ islands and genes in human and mouse. Proc Natl Acad Sci USA 1993, 90(24):11995-11999.

44. Bird A: DNA methylation patterns and epigenetic memory. Genes Dev 2002, 16(1):6-21.

45. Kim TH, Barrera LO, Zheng $M$, Qu C, Singer MA, Richmond $T A$, Wu $Y$, Green RD, Ren B: A high-resolution map of active promoters in the human genome. Nature 2005, 436(7052):876-880.

46. Weber M, Schubeler D: Genomic patterns of DNA methylation: targets and function of an epigenetic mark. Curr Opin Cell Biol 2007, 19(3):273-280.

47. Black AR, Black JD, Azizkhan-Clifford J: Sp1 and kruppel-like factor family of transcription factors in cell growth regulation and cancer. J Cell Physiol 2001, 188(2):143-160

48. Tang QQ, Jiang MS, Lane MD: Repressive effect of Sp1 on the C/EBPalpha gene promoter: role in adipocyte differentiation. Mol Cell Biol 1999, 19(7):4855-4865

49. Bernot D, Barruet E, Poggi M, Bonardo B, Alessi MC, Peiretti F: Downregulation of tissue inhibitor of metalloproteinase-3 (TIMP-3) expression is necessary for adipocyte differentiation. J Biol Chem 2010, 285(9):6508-6514.

50. Callejas NA, Boscá L, Williams CS, Du BR, Martín-Sanz P: Regulation of cyclooxygenase 2 expression in hepatocytes by CCAAT/enhancerbinding proteins. Gastroenterology 2000, 119(2):493-501.

51. Laborda J: $36 \mathrm{~B} 4$ CDNA used as an estradiol-independent mRNA control is the CDNA for human acidic ribosomal phosphoprotein PO. Nucleic Acids Res 1991, 19(14):3998.

doi:10.1186/1471-2199-12-52

Cite this article as: Rivero et al:: Characterization of a proximal Sp1 response element in the mouse Dlk2 gene promoter. BMC Molecular Biology 2011 12:52.

\section{Submit your next manuscript to BioMed Central and take full advantage of:}

- Convenient online submission

- Thorough peer review

- No space constraints or color figure charges

- Immediate publication on acceptance

- Inclusion in PubMed, CAS, Scopus and Google Scholar

- Research which is freely available for redistribution 